\title{
DIPNECH (Diffuse Idiopathic Pulmonary Neuroendocrine Cell Hyperplasia): A Rare Syndrome or Undiagnosed?
}

\section{Rafaela B. Campanha*, Cristina Matos and Fernando Nogueira}

Centro Hospitalar de Lisboa Ocidental, Portugal

\begin{abstract}
Diffuse idiopathic pulmonary neuroendocrine cell hyperplasia (DIPNECH) is considered a rare syndrome and knowledge of its pathophysiology is scarce. Classified as pre-neoplastic lesion of carcinoid tumours currently there are many questions regarding the best approach to follow-up and treatment this patients. Mainly affects females, there is no apparent relationship to smoking habit and is often confused with obstructive airway disease. The diagnosis is histological and sometimes can be observed simultaneously a triple pattern consisting of DIPNECH, tumourlets and carcinoid tumour.
\end{abstract}

We report the case of a 35-years-old woman, non-smoker with DIPNECH in association with typical carcinoid tumour and tumourlets.

Keywords: DIPNECH; Carcinoid tumour; Tumourlets; Case report

\section{Introduction}

Diffuse idiopathic pulmonary neuroendocrine cell hyperplasia (DIPNECH) is considered a rare syndrome that affects the bronchial tree and is often confused with chronic obstructive pulmonary disease $[1,2]$. The spectrum of disease ranges between the foci of hyperplasia less than $5 \mathrm{~mm}$ without involvement of the basal membrane that are designate tumourlets and those who have more than $5 \mathrm{~mm}$ longer and invade the basement membrane designate carcinoid tumours [1]. The diagnosis is histological and it is believed that the triple component simultaneously (DIPNECH, tumourlets and carcinoid tumour) may be underdiagnosed [2].

\section{Case History}

A 35-year-old woman with a history of rhinitis, no smoking and no history of allergies was initially treated with nasal fluticasone and levocetirizine. Family history and socio-professional history were without clinical relevance. Referenced to the Pulmology service by her general doctor with complaints of daily cough with sputum with 3 years of evolution with a worsening at the last 3 months and associated with dyspnoea with physical activities. The pulmonary function tests showed decreased of forced expiratory flow at 75\% and an IgE: 29 and negative Phadiatop with negative skin sensitivity tests. The chest radiograph was normal. The report of the first chest computed tomography (CT) revealed only slight left pleural thickening (this time the images were not displayed). The therapy was optimized with montelukast, nasal budesonide and salbutamol in SOS and there was observed an improvement in dyspnea but maintain a dry irritating cough. In followup visit after 2 years there was a history of weight loss about $10 \mathrm{~kg}$ in 8 months and it was decided to repeat chest CT that revealed in the right lower lobe two small nodular hyperdense solid formations, one with $5 \mathrm{~mm}$ and another with $2 \mathrm{~mm}$ and in the lower left lobe a solid hyperdense nodular lesion with $18 \mathrm{~mm}$ and well-defined contours. Physical exam and blood tests were normal (Figure 1). A bronchoscopy was performed and revealed no alterations. The case was discussed at a multidisciplinary meeting and was decided to do a PET-68GsSRP that revealed faint fixing 68Ga-DOTANOC in the lung injury already known located in the posterior part of the inferior left lung (carcinoid tumour with low expression of somatostatin receptors 2, 3 or 5). A left lower lobectomy to get histological and surgical treatment was performed and the pathology report revealed a neuroendocrine tumour, morphologically without necrosis or mitosis and histological

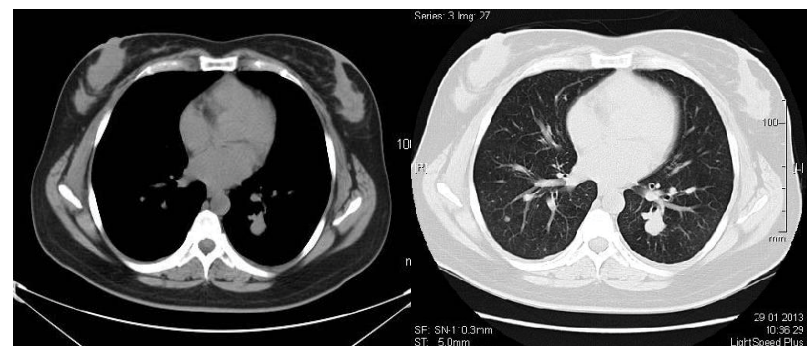

Figure 1: Chest CT showing on the right lower lobe two small nodular formations, one with $5 \mathrm{~mm}$ and another with $2 \mathrm{~mm}$ with well-defined lines and in the lower left lobe a solid hyperdense nodule with $18 \mathrm{~mm}$ and well-defined contours.

corresponding to a typical carcinoid tumour with multiple foci of endocrine cell hyperplasia and tumourlets.

\section{Discussion}

The DIPNECH was first described in 1950 but only in 1999 was considered by the World Health Organization (WHO) as a preneoplastic carcinoid syndrome [3-5]. There are few cases described in the literature and little is known about the etiology, treatment and follow-up of this disease that appears to have a good prognosis $[2,4]$.

The spectrum of the disease is highly variable and diagnosis is often confused with obstructive lung disease. The DIPNECH is considered precursor of tumourlets and typical and /or atypical carcinoid [6,7].

Previous studies report that about two thirds of patients with carcinoid tumors have hyperplasia of neuroendocrine cells and it is

*Corresponding author: Rafaela B. Campanha, M.D., Centro Hospitalar de Lisboa Ocidental, Portugal, Tel: 00351912725591; E-mail: rafaela_ campanha@hotmail.com

Received July 14, 2015; Accepted August 24, 2015; Published August 30, 2015

Citation: Campanha RB, Matos C, Nogueira F (2015) DIPNECH (Diffuse Idiopathic Pulmonary Neuroendocrine Cell Hyperplasia): A Rare Syndrome or Undiagnosed? J Pulm Respir Med 5: 286. doi:10.4172/2161-105X.1000286

Copyright: (C) 2015 Campanha RB, et al. This is an open-access article distributed under the terms of the Creative Commons Attribution License, which permits unrestricted use, distribution, and reproduction in any medium, provided the original author and source are credited. 
thought that this occurs almost always in the context of fibrosis and/ or airway inflammation. When these foci of hyperplasia reach the basement membrane and are less that $5 \mathrm{~mm}$ are designate tumourlets and may be localized or diffuse when reach more than $5 \mathrm{~mm}$ in diameter shall be termed carcinoid tumour. However the three entities DIPNECH, tumourlets and carcinoid tumour (typical or atypical) may coincide simultaneously more localized or diffuse in the bronchial tree.

In the most published cases the profile of patients is similar: high prevalence of females (95\%), with ages ranging between 30 to 75 years, with no relationship to smoking and the most frequent complaints are dry and irritative cough associated with dyspnoea however asymptomatic patients were also report [2,7]. The cause of higher prevalence of the syndrome in females remains a big question but one hypothesis is that there may be a hormonal basis of the disease pathogenesis. Spirometry test usually confirm an airway obstruction that can range from mild to severe and this is why this syndrome is often easily confused with obstructive disease in spite of some patients showing evidence of normal respiratory function. The gold standard definitive diagnosis is made by histological evaluating of the lung tissue usually obtained by surgical resection [7-9]. In a recent study it was proposed clinical diagnostic criteria for DIPNECH that incorporate demographic, pulmonary physiology, HRCT imaging, and transbronchial and surgical lung biopsy data, but additional research is needed to validate this criteria [10].

The syndrome appears to have a benign course with most of the series demonstrate a survival rate at 5 years of $80-90 \%$. However given the potential of transformation into malignant lesion the main questions are related to the monitoring and treatment of these patients [2,7-9].

Knowing that the focal neuroendocrine hyperplasia cells and tumourlets have the potential to produce new carcinoid tumours the first major issue is related with the follow-up of these patients often asymptomatic and relatively young. In our case we have chosen to follow the patient by chest CT which revealed that small nodules of the right lower lobe $(2 \mathrm{~mm}$ and $5 \mathrm{~mm})$ were radiologically stable and although we cannot affirm that they correspond to tumourlets this hypothesis cannot be excluded in spite of the definitive diagnosis being confirmed only by histology. The PET-Dotanoc has more costs however in the near future it could be the method of choice for follow-up this patients because it has greater sensitivity than CT combined with a lower iatrogenic damage with radiation [11].

Major challenges relate to the treatment of DIPNECH are still need answers. What to do? Keep only clinical and radiological monitoring? Chose another type of therapy since these patients have pre-neoplastic lesions? Some studies have evaluated the possibility of using short courses of corticosteroids, others chose to use somatostatin analogues, other prefer short cycles of chemotherapy and the majority choose monitoring only. Many of these works are still being performed at the present and the results are still inconclusive. In DIPNECH area at the present we have more questions than answers but this syndrome is being recognized and diagnosed with more frequency and surely will be possible to better understand the etiology, the best method to monitor disease progression and offer the most appropriate treatment to improve the prognosis and life quality of patients.

\section{Ethical Disclosures}

\section{Protection of human and animal subjects}

The authors declare that no experiments were performed on humans or animals for this study.

\section{Confidentiality of data}

The authors declare that they have followed the protocols of their work center on the publication of patient data and that all the patient included in the study received sufficient information and gave their written informed consent to participate in the study.

\section{Right to privacy and informed consent}

The authors have obtained the consent of the patient mentioned in the article.

\section{Conflicts of interest}

The authors have no conflicts of interest to declare.

\section{References}

1. Montoro Zulueta FJ, Martínez Prieto M, Verdugo Cartas MI, Esteban Rodriguez I, Hernández Muñiz S (2012) Diffuse idiopathic pulmonary neuroendocrine cell hyperplasia with multiple synchronous carcinoid tumors. Arch Bronconeumol 48: $472-475$.

2. Tippett VM, Wathen CG (2010) Diffuse idiopathic neuroendocrine cell hyperplasia: an unusual cause of breathlessness and pulmonary nodules. BMJ Case Rep 1-4

3. Travis WD (2014) Advances in neuroendocrine lung tumors. Ann Oncol Supp 7: vii65-71.

4. Warth A, Herpel E, Schmähl A, Storz K, Schnabel P (2008) Diffuse idiopathic pulmonary neuroendocrine cell hyperplasia (DIPNECH) in association with an adenocarcinoma: a case report. J Med Case Rep 2: 21.

5. Brambilla E, Travis WD, Colby TV, Corrin B, Shimosato Y (2001) The new World Health Organization classification of lung tumours. Eur Respir J 18: 1059-1068.

6. Gorshtein A, Gross DJ, Barak D, Strenov Y, Refaeli Y, et al. (2012) Diffuse idiopathic pulmonary neuroendocrine cell hyperplasia and the associated lung neuroendocrine tumors: clinical experience with a rare entity. Cancer 118: 612619

7. Coletta EN, Voss LR, Lima MS, Arakaki JS, Câmara J, et al. (2009) Diffuse idiopathic pulmonary neuroendocrine cell hyperplasia accompanied by airflow obstruction. J Bras Pneumol 35: 489-494.

8. Davies SJ, Gosney JR, Hansell DM, Wells AU, du Bois RM, et al. (2007) Diffuse idiopathic pulmonary neuroendocrine cell hyperplasia: an under-recognised spectrum of disease. Thorax 62: 248-252.

9. Adams H, Brack T, Kestenholz P, Vogt P, Steinert HC, et al. (2006) Diffuse idiopathic neuroendocrine cell hyperplasia causing severe airway obstruction in a patient with a carcinoid tumor. Respiration 73: 690-693.

10. Carr LL, Chung JH, Duarte Achcar R, Lesic Z, Rho JY, et al. (2015) The clinical course of diffuse idiopathic pulmonary neuroendocrine cell hyperplasia. Chest 147: 415-422.

11. Kayani I, Conry BG, Groves AM, Win T, Dickson J, et al. (2009) A comparison of 68Ga-DOTATATE and 18F-FDG PET/CT in pulmonary neuroendocrine tumors. J Nucl Med 50: 1927-1932. 